\title{
Longitudinal Associations between Parental Support and Parental Knowledge on Behavioral and Emotional Problems in Adolescents
}

\author{
Olalla Cutrín (i) ${ }^{1}$ Lorena Maneiro ${ }^{1,2} \cdot$ Yasmynn Chowdhury ${ }^{3} \cdot$ Stephen S. Kulis $^{4}$ - Flavio F. Marsiglia ${ }^{4}$ \\ José Antonio Gómez Fraguela ${ }^{1}$
}

Received: 21 October 2021 / Accepted: 11 December 2021 / Published online: 23 December 2021

(c) The Author(s) 2021

\begin{abstract}
When testing longitudinal effects of parenting practices on adolescent adjustment, an integrated consideration of externalizing and internalizing behaviors is a gap in research. This study analyzed how parental support and parental knowledge directly and indirectly influence both antisocial behavior and emotional problems. The sample had 642 adolescents aged 12-15 (mean age $=12.49 ; 45.4 \%$ females) from Spain, who participated in a three-year long study. The results showed longitudinal bidirectional associations between parental support and parental knowledge. Only parental knowledge, however, directly predicted antisocial behavior and emotional problems. Parental support had an indirect effect on outcomes through the mediating effect of parental knowledge. This study has practical implications by indicating that increasing parental knowledge should be the target of educational-prevention programs.
\end{abstract}

Keywords Parenting practices $\cdot$ Adolescent adjustment $\cdot$ Mediation effects $\cdot$ Prevention

\section{Introduction}

Research has demonstrated consistently that negative parenting practices are a robust risk factor for antisocial behavior and delinquency (Hoeve et al., 2009), as well as emotional problems in adolescence (Garthe et al., 2015). Both antisocial behavior and emotional problems are quite common during adolescence. The most recent findings from the Health Behavior in School-aged Children study in Spain indicated that $13.2 \%$ of adolescents committed shoplifting, $8.8 \%$ were involved in acts of vandalism, and $16 \%$ had been involved in a violent dispute with a teacher (Moreno et al., 2019). Among Spanish youth aged 15 to 24 years old, prevalence rates for depression and anxiety were $1.22 \%$ to $2.06 \%$, respectively (Ministerio de Sanidad, Consumo y Bienestar Social \& Instituto Nacional de Estadística, 2017).

Olalla Cutrín

olalla.cutrin@usc.es

1 Universidade de Santiago de Compostela, Santiago de Compostela, Spain

2 Leiden University, Leiden, The Netherlands

3 University of Oxford, Oxford, UK

4 Arizona State University, Phoenix, AZ, USA
The co-occurrence of externalizing and internalizing problems during adolescence is well-established (Loeber \& Burke, 2011), as are the negative consequences of antisocial behavior (DeLisi, 2016) and mental health problems (Hughes \& Gullone, 2008) for the psychological, social and economic well-being of youth, their families, and their broader communities. Despite the high co-occurrence of these issues and the relevance of parenting practices in adolescent adjustment, there is a gap in research on how the interrelation of parenting practices during adolescence influences both behavioral and emotional problems. This work seeks to fill gaps in the extant literature by analyzing longitudinal mediation effects of parental support and parental knowledge on both antisocial behavior and emotional problems in Spanish adolescents.

\section{Parental Knowledge as a Predictor of Antisocial Behavior and Emotional Adjustment}

Parental knowledge (i.e., information that parents have about their child's activities, whereabouts, or friendships) is one of the most robust factors predicting adolescent antisocial behavior (Kerr \& Stattin, 2000; Stattin \& Kerr, 2000). Research has demonstrated that the level of parental knowledge, rather than a supervision strategy involving active monitoring, is linked to adolescent behavior (Eaton et al., 2009). In this regard, 
adolescent willingness to disclose information to parents is a strong predictor of higher levels of parental knowledge and lower levels of antisocial behavior (Kerr et al., 2010). There is enduring evidence of a strong association between lower levels of parental knowledge and higher levels of adolescent antisocial behavior, both violent and non-violent, as well as substance use behaviors (e.g., Cutrín et al., 2019). Similarly, levels of parental knowledge are negatively correlated with and/or predictive of occurrences of emotional problems, such as symptoms of anxiety and depression (Bacchini et al., 2011), with more consistent evidence for the effects of parental knowledge on depression than on anxiety (Yap et al., 2014).

\section{Parental Support as a Predictor of Antisocial Behavior and Emotional Adjustment}

A supportive parental style, based on acceptance, affection, attachment, warmth, communication, and intimacy, has been demonstrated generally to be a protective factor against antisocial behavior (Hoeve et al., 2009) and substance use (Calafat et al., 2014), and is associated with better adolescent adjustment. Overall, lower levels of parental support have been associated with higher levels of antisocial behavior in adolescence (Álvarez-García et al., 2016), drug use and externalizing behavior (Parra \& Oliva, 2006). Likewise, lower levels of perceived parental support and lack of parental displays of warmth are associated with a higher risk of developing depressive symptoms and anxiety in adolescence (Yap et al., 2014), and parental support is more strongly associated with depressive symptoms than with anxiety symptoms (Pinquart, 2017).

\section{Mediation Parental Support-Knowledge Influencing Adolescent Behavior and Adjustment}

From a developmental theoretical perspective, which is intrinsically a holistic-integrative approach, the risk factors promoting maladjustment in adolescence interact with each other at early stages (Compas, 2004). Adolescent behavior is viewed as the result of a bioecological process in which different risk factors are linked to one another depending on the interaction of different systems and contexts (Bronfenbrenner, 2005). Family is one of the most important systems that affects adolescent development (Magnusson \& Stattin, 2006). Within the family system, developmental theory showed that the interrelation between multiple negative parenting practices works as a risk factor for developing maladjusted outcomes (Granic et al., 2003).

As components of the same system, positive parentadolescent relationships and parental knowledge are linked in a bi-directional way (Walters, 2019). However, parentadolescent communication processes have been evaluated most often as predictors of disclosure and knowledge (Laird
\& Zeringue, 2019), and not the reverse way. From a developmental perspective, parent-adolescent relationships are shaped by previous patterns of family interactions (Collins \& Steinberg, 2008), such that the establishment of a supportive and communicative family atmosphere during childhood promotes adolescent disclosure and parental knowledge during adolescence (Kerr et al., 2010). Positive open communication, closeness, and supportive family bonds facilitate parenting practices involving supervision and knowledge (Fletcher et al., 2004). As has been found in other studies, parent-child relationships involving warmth (Blodgett Salafia et al., 2009) and perceived support (TiltonWeaver, 2014) promote adolescents' willingness to spontaneously disclose information about their lives, and such disclosure is the critical source and main predictor of parental knowledge (Stattin \& Kerr, 2000). Therefore, from a developmental perspective, warm and supportive parentchild relationships are the prerequisite for child disclosure and, ultimately, parental knowledge (Liu et al., 2020).

Previous studies have suggested that parental support does not even exert a direct effect on antisocial behavior in adolescence (e.g., Cutrín et al., 2015; de Kemp et al., 2007), but supportive parent-child relationships do influence such behaviors through the degree of parental supervision or parental knowledge (Burfeind \& Bartusch, 2016). Research has consistently found that higher levels of parental support are indirectly related to lower levels of antisocial behavior (Yun et al., 2016) and lower levels of antisocial beliefs (Dane et al., 2012) through the mediating role of parental knowledge. Parental support appears to be indirectly and inversely associated with antisocial behavior and substance use through the mediation of parental knowledge among both the general adolescent population and juvenile offenders (Cutrín et al., 2017). However, this study had a cross-sectional design, and it could not confirm any hypotheses regarding directionality in the parenting variables.

Despite the vast body of research on externalizing problems and antisocial behavior, there is limited research on the mediation effects of parental support through parental knowledge on internalizing and emotional problems in adolescence. A study on the effects of parental support on depressive symptoms in children and pre-adolescents has analyzed mediation effects of parentchild attachment measured, in part, as open parent-child communication (Yan et al., 2017). That study found that children whose parents support their autonomy showed fewer depressive symptoms by establishing a more secure attachment. To the best of our knowledge, there is no prior research on how parental knowledge mediates the effects of parental support on internalizing problems, as well as on both behavioral and emotional problems in adolescence. 
From a developmental and holistic-integrative approach, the study of the longitudinal interrelation of the main positive parenting practices influencing co-occurring behavioral and emotional problems is warranted to better understand adolescent development. In addition, although developmental theory suggests a specific direction for the effects of parental support and parental knowledge on adolescent adjustment, none prior research has empirically confirmed this finding by testing the mediation effects of both parenting practices. By addressing this gap around considering an integrative approach on parenting practices and adolescent adjustment, and the need for longitudinal designs, this study will contribute knowledge on the effects of parental support and parental knowledge on both externalizing and internalizing problems and may contribute to the development of prevention strategies, at both behavioral and emotional levels, for adolescents and their parents.

\section{The Current Study}

To address gaps in the extant literature, the current study analyzed bi-directional relationships and longitudinal mediation effects of parental support and parental knowledge on antisocial behavior (i.e., aggression, rule breaking, and drug-use problems) and emotional problems in a general (school-based) population of Spanish adolescents. Three main hypotheses guided the current study from a holistic and developmental perspective. Bi-directional positive effects between parental support and parental knowledge were expected; that is, higher levels of parental support would predict higher levels of parental knowledge, and higher levels of parental knowledge would predict higher levels of parental support one year later (Hypothesis 1). As robust predictors for externalizing and internalizing problems, it was also expected that parental support and parental knowledge would negatively predict antisocial behavior and emotional problems (Hypothesis 2). Finally, because parental support and knowledge were expected to be bi-directionally related, potential mediation effects were tested in both directions. However, based on developmental theory and previous research, only a unidirectional pathway was expected to be significant: that parental support indirectly influences adolescent adjustment through the mediating role of parental knowledge (Hypothesis 3).

\section{Methods}

\section{Sample}

The current study engaged a sample of students who participated in a three-year (2017-2019) longitudinal study across 11 public secondary schools in Galicia (NW Spain). At baseline (T1), the sample included 642 adolescents enrolled in the first grade of Spanish compulsory secondary education $\left[1^{\text {st }}\right.$ grade ESO; equivalent to $7^{\text {th }}$ grade in the US]. Adolescents ranged in age from 12 to $15(M=12.49 ; S D=0.67 ; 92 \%$ were age typical for their grade level, $12-13$ years old) and $45.4 \%$ were female. The second wave of the data collection (T2) took place approximately 12 months after the initial assessment and included 493 adolescents aged 13-16 $(M=13.36 ; S D=0.59)$, $48.3 \%$ females. At T2, $99.6 \%$ of adolescents were enrolled in the second grade of compulsory secondary education $\left[2^{\text {nd }}\right.$ grade $\mathrm{ESO}]$ and $0.4 \%$ were repeating $1^{\text {st }}$ grade ESO. The third wave (T3), which was carried out two years after the initial assessment, included 414 participants aged 14-16 $(M=14.18$; $S D=0.40), 49.0 \%$ females, of which 392 were followed up from both $\mathrm{T} 1$ and $\mathrm{T} 2$. At T3, 97.8\% of adolescents were enrolled in the third grade of compulsory secondary education [ $3^{\text {rd }}$ grade ESO] and $2.2 \%$ were repeating $2^{\text {nd }}$ grade ESO. At the beginning of the study, the majority of participants lived with both parents $(78.3 \%)$, whereas $16.8 \%$ lived only with their mother, $2.3 \%$ lived only with their father, and $2.5 \%$ lived with other relatives. More than $90 \%$ of the sample was white, born in Galicia, and came from middle and low-middle socioeconomic backgrounds.

The level of attrition was $23.2 \%$ between $\mathrm{T} 1$ and $\mathrm{T} 2$ and $38.9 \%$ between T1 and T3. Significant differences were found between respondents and non-respondents at T3 with regard to baseline gender $\chi^{2}(1)=6.19, p=0.013$, age $t(639)=9.40, p<0.001$, antisocial behavior $F(1,578)=$ $56.455, p<0.001$, and emotional problems $F(1,615)=$ $11.221, p=0.001$. Non-respondents at T3 were more likely to be male, older, and reporting higher levels of antisocial behavior and emotional problems at $\mathrm{T} 1$ than respondents at follow-up.

\section{Measurements}

\section{Parental knowledge (T1-T2)}

The degree of parental knowledge regarding adolescents' whereabouts, activities, and friendships was measured by a self-reported scale composed of 8 items (Kerr \& Stattin, 2000; Stattin \& Kerr, 2000) and validated in community Spanish adolescents (Cutrín et al., 2019) (e.g., "Your parents know what you do during your free time"). Items were scored from 0 (never) to 3 (always), higher scores indicating higher levels of knowledge. This scale presented an internal consistency of $\alpha=0.81$ in $\mathrm{T} 1$ and $\alpha=0.80$ in $\mathrm{T} 2$.

\section{Parental support (T1-T2)}

The perception of parental warmth, responsiveness, and closeness to parents was assessed by means of a 
Fig. 1 Proposed Model to Predict Antisocial Behavior and Emotional Problems. All the direct effects in the model controlled for gender and age in T1 (both observed variables).

The direct effects on the outcomes also controlled for antisocial behavior and emotional problems in $\mathrm{T} 1$ (both observed variables). Factor loadings of support ranged from 0.61 to 0.81 in $\mathrm{T} 1$ and 0.69 to 0.81 in $\mathrm{T} 2$; factor loadings of knowledge ranged from 0.46 to 0.66 in $\mathrm{T} 1$ and 0.45 to 0.73 in $\mathrm{T} 2$; factors loadings of antisocial behavior ranged from 0.48 to 0.86 and factor loadings of emotional problems from 0.42 to 0.75 ; all of them being significant $(p<0.001)$

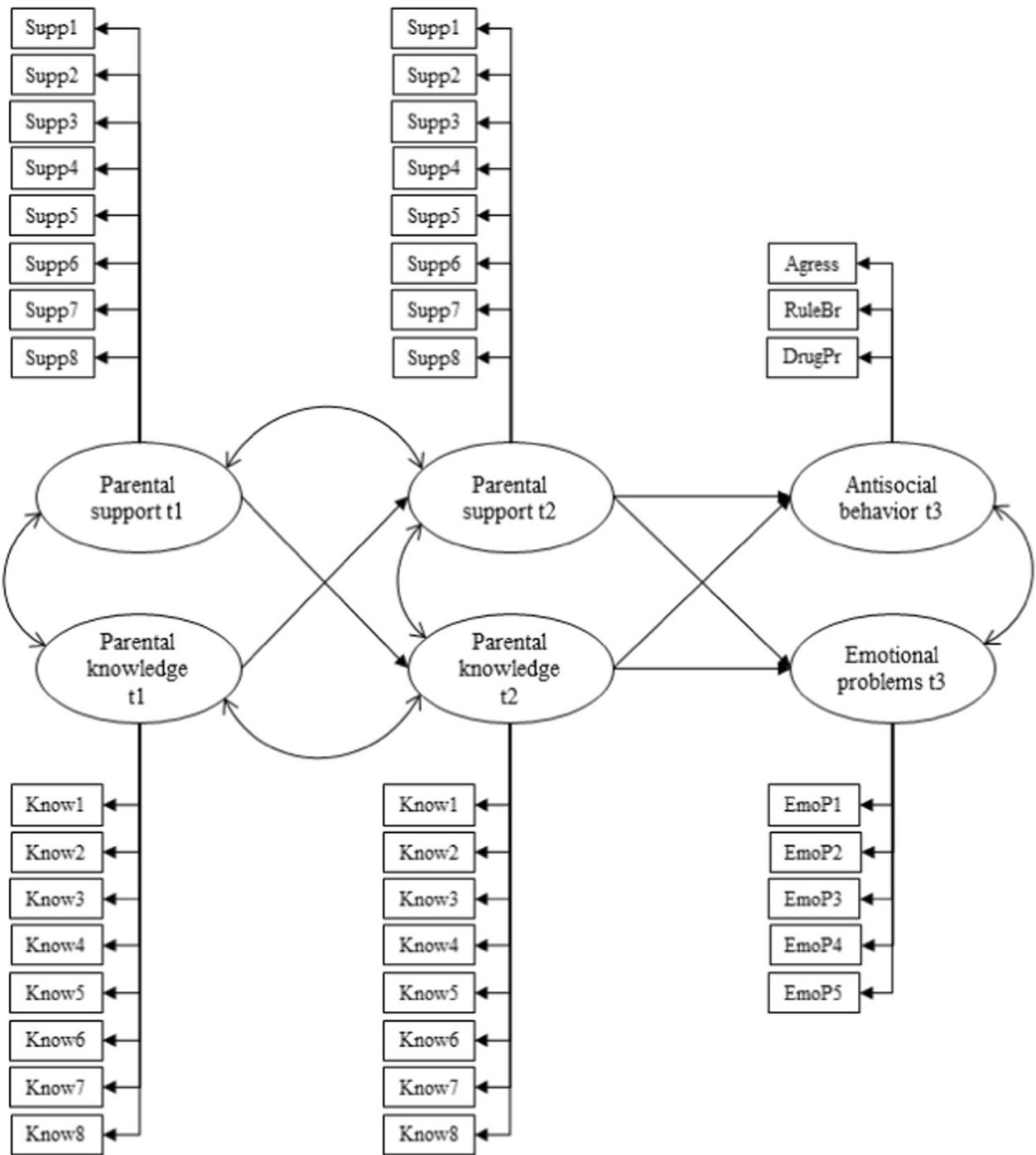

self-reported scale, validated in community Spanish adolescents (Oliva et al., 2007). The scale was composed of 8 items (e.g., "You feel supported and understood") scored in a 4-point scale ranging from 0 (never) to 3 (always), higher scores indicating higher levels of support. The internal consistency of the scale was $\alpha=0.90$ in $\mathrm{T} 1$ and $\alpha=0.91$ in $\mathrm{T} 2$.

\section{Antisocial behavior (T1-T3)}

Three self-reported scales from the short Spanish version of the Antisocial Behavior Questionnaire (ABQ; Luengo et al., 1999) were used to evaluate aggression (6 items; $\alpha=0.72$; e.g., "Fighting and hitting someone"), rulebreaking ( 6 items; $\alpha=0.63$; e.g., "Spending the night out without permission"), and drug-related problems, that is, unhealthy and antisocial behaviors derived from substance abuse ( 6 items; $\alpha=0.63$; e.g., "Having five or more drinks on one occasion"). Items were scored from 0 (never) to 3 (very often), higher scores indicating higher levels of antisocial behavior. The composite from these three scales showed an internal consistency of $\alpha=0.81$ in T1 and $\alpha=$ 0.64 in $\mathrm{T} 3$.

\section{Emotional problems (T1-T3)}

The self-reported scale on emotional symptoms from the Spanish version of the Strengths and Difficulties Questionnaire (SDQ; Ortuño-Sierra et al., 2015) was used to assess the presence of nervousness, sadness, or worry in adolescents (e.g., "I often feel sad or discouraged or feel like crying"). This scale was composed of 5 items scored from 0 (it's not true) to 2 (absolutely true), higher scores indicating higher levels of emotional problems. The internal consistency of this scale was $\alpha=0.71$ in $\mathrm{T} 1$ and $\alpha=$ 0.73 in $\mathrm{T} 3$. 


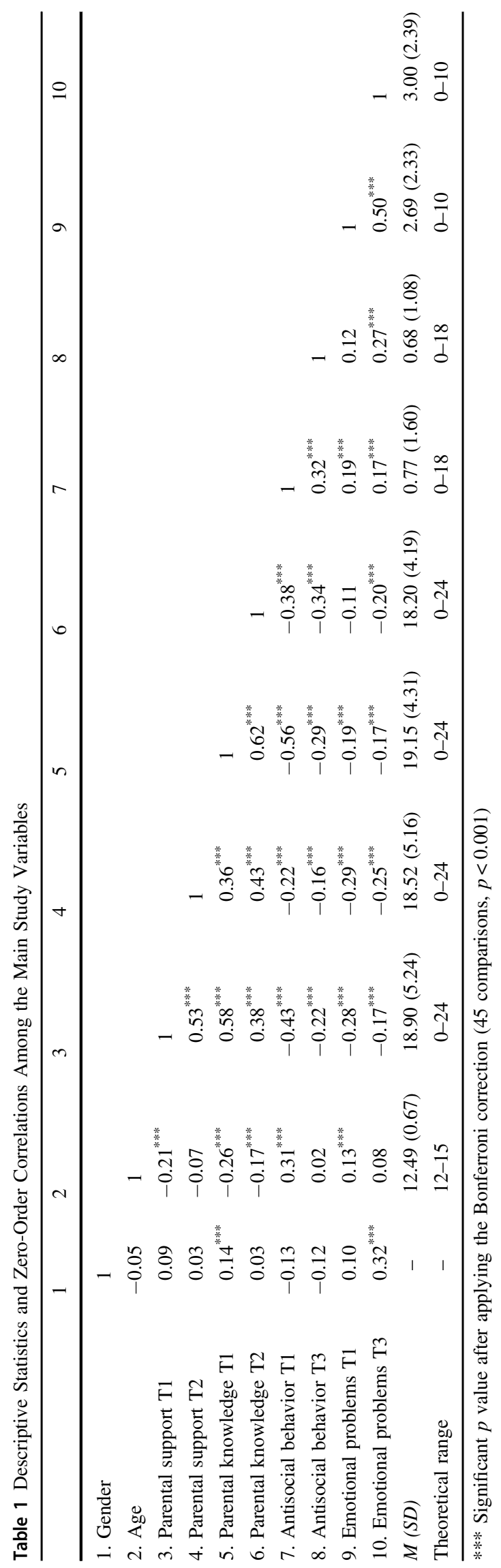

\section{Procedure}

This study was approved by the Galician Autonomous Community's Government and met ethical standards established by the Santiago de Compostela University's bioethics committee. The investigators presented the study to the principals of 24 secondary schools, selected by convenience sampling. In the secondary schools that agreed to participate in the longitudinal study (11 schools), all students enrolled in the first grade (equivalent to $7^{\text {th }}$ grade in the US) were invited to participate and more than $90 \%$ of them completed the questionnaire.

Qualified psychologists from the research group visited the schools, explained the objectives of the research, and provided proper instructions to the respondents. Adolescents filled out the questionnaires in classroom sessions of approximately 50 minutes. Parents provided informed consent each year before the start of data collection according to the schools' internal regulations. Passive consent was the most common approach, except in two schools that implemented active consent protocols. Parents received an informational note from their children, who had to return the signed consent to their teacher or school counselor. Subsequently, adolescents provided their assent before completing the questionnaire. Adolescent participation was voluntary, and their responses were anonymous and confidential. Three waves of data collection were implemented during a three-year period, with intervals of approximately 12 months between observations.

\section{Statistical Analyses}

Firstly, descriptive statistics and zero-order correlations among all the study variables (created by the mean of the items) were produced in IBM SPSS 25. The Bonferroni correction was applied to account for multiple comparisons. Next, structural equation modeling (SEM) was conducted in Mplus 7.4 using the robust maximum likelihood (MLR) estimator to adjust for non-normal distributions. SEM was used to test the effect of parenting practices (i.e., parental support and parental knowledge) on both antisocial behavior and emotional problems (see Fig. 1 for specific indicators of each latent variable). Parental support in $\mathrm{T} 1$ was included as a predictor of parental knowledge in $\mathrm{T} 2$ and parental knowledge in $\mathrm{T} 1$ as predictor of parental support in T2. Parental support and knowledge were set to intercorrelate at $\mathrm{T} 1$ as well as at $\mathrm{T} 2$. Intracorrelations between parental support at $\mathrm{T} 1$ and $\mathrm{T} 2$ and between parental knowledge at $\mathrm{T} 1$ and $\mathrm{T} 2$ were also specified in the model. Both parenting variables at $\mathrm{T} 2$ were included as predictors of antisocial behavior and emotional problems in T3. The model controlled for 
gender, age, antisocial behavior, and emotional problems in T1. Because these variables serve only for control purposes, they were included as observed variables in the model (antisocial behavior and emotional problems were measured as the mean of the component items) to conform as much as possible to the standards on the number of indicators that should be used in SEM (Bentler \& Chou, 1987). The model also adjusted statistically for the schoollevel clustering of data to account for between-school variance and employed full information maximum likelihood (FIML) estimation to account for attrition to the posttests and item missing data.

Potential mediation effects of parental support as well as parental knowledge on both externalizing and internalizing problems were also tested in the model. A combination of Maximum Likelihood (ML) and bootstrapping $(b=5000)$ were used in order to maximize accurate estimations under a non-normal distribution and estimate bias-corrected $95 \%$ confidence intervals for indirect effects (Hancock \& Liu, 2012). The following goodnessof-fit indexes were used to evaluate the model fit: $\chi^{2} / D F$, CFI, RMSEA, and SRMR, with $\chi^{2} / D F<2-3$, CFI values of 0.95 or higher, and RMSEA and SRMR values lower or equal to 0.05 considered indicators of optimal model fit, whereas values of $\chi^{2} / D F<4, \mathrm{CFI}>0.90$, and RMSEA and SRMR between 0.08 and 0.10 indicated adequate model fit (Hu \& Bentler, 1999).

Finally, a sensitivity analysis was conducted to check the robustness of measurement and modeling. The model was analyzed using only rule-breaking as the antisocial behavior outcome to confirm whether the results can be replicated with a homogeneous measure of antisocial behavior, rather than the heterogeneous measure that also includes aggression, drug use and drugrelated problems.

\section{Results}

This study reports all the results of the tests of hypotheses, whether significant or not. Table 1 shows the descriptive statistics and intercorrelations among all the study variables. Both parenting practices had very high means, while antisocial behavior and emotional problems had low to very low means. After applying the Bonferroni correction, threshold levels of significance were set at 0.001 (45 comparisons). Correlations showed that females reported significantly higher levels of knowledge at $\mathrm{T} 1$ and emotional problems at T3 than males. Age was significantly and inversely associated with parental support at $\mathrm{T} 1$ and parental knowledge at $\mathrm{T} 1$ and $\mathrm{T} 2$, and positively associated with antisocial behavior and emotional problems at T1. Parental practices were significantly and positively related with each other. Specifically, both parental support and parental knowledge evidenced high stability over time, showing strong positive correlations between the first and second waves of data collected. Overall, both parenting practices were negatively associated with antisocial behavior and emotional problems after one-year and two-year follow-ups. Significant, positive correlations were found between antisocial behavior and emotional problems, except antisocial behavior at $\mathrm{T} 3$ with emotional problems at $\mathrm{T} 1$.

\section{Bi-Directional and Longitudinal Associations Between Parental Support and Parental Knowledge on Antisocial Behavior and Emotional Problems}

Figure 1 shows the structural equation model predicting antisocial behavior and emotional problems. The model showed adequate values of goodness-of-fit indices, $\chi^{2}(863)=1565.23, p<0.001, \chi^{2} / \mathrm{DF}=1.81, \mathrm{CFI}=0.91$,

Table 2 Results of SEM Predicting Antisocial Behavior and Emotional Problems

\begin{tabular}{|c|c|c|c|c|c|c|c|c|}
\hline & \multicolumn{2}{|c|}{ Parental support T2 } & \multicolumn{2}{|c|}{ Parental knowledge T2 } & \multicolumn{2}{|c|}{ Antisocial behavior T3 } & \multicolumn{2}{|c|}{ Emotional problems T3 } \\
\hline & B (SE) & $\beta$ & $\mathrm{B}(\mathrm{SE})$ & $\beta$ & B (SE) & $\beta$ & $\mathrm{B}(\mathrm{SE})$ & $\beta$ \\
\hline Gender & $-0.08(0.05)$ & -0.07 & $0.04(0.07)$ & 0.04 & $-0.07(0.05)$ & -0.07 & $0.23(0.03)$ & $0.32^{* * *}$ \\
\hline Age & $0.01(0.05)$ & 0.01 & $-0.09(0.05)$ & -0.12 & $-0.06(0.06)$ & -0.07 & $0.02(0.03)$ & 0.04 \\
\hline $\mathrm{AB} \mathrm{T} 1$ & & & & & $0.17(0.07)$ & $0.49^{* *}$ & $-0.00(0.02)$ & -0.00 \\
\hline EP T1 & & & & & $0.01(0.02)$ & 0.05 & $0.07(0.01)$ & $0.46^{* * * *}$ \\
\hline Support T1 & & & $0.37(0.08)$ & $0.42^{* * *}$ & & & & \\
\hline Knowledge $\mathrm{T} 1$ & $0.55(0.07)$ & $0.46^{* * *}$ & & & & & & \\
\hline Support T2 & & & & & $0.10(0.09)$ & 0.10 & $-0.05(0.06)$ & -0.08 \\
\hline Knowledge T2 & & & & & $-0.46(0.20)$ & $-0.41^{* * *}$ & $-0.15(0.06)$ & $-0.20^{*}$ \\
\hline $\mathrm{R}^{2}$ & 0.20 & & 0.21 & & 0.45 & & 0.44 & \\
\hline
\end{tabular}

Note. Gender was coded as 0-male, 1-female. $\mathrm{AB}=$ antisocial behavior. $\mathrm{EP}=$ emotional problems. Support $=$ parental support. Knowledge $=$ parental knowledge

${ }^{*} p<0.05{ }^{* *} p<0.01{ }^{* * *} p<0.001$ 
Fig. 2 Significant Paths in the Structural Equation Model Tested. Non-significant paths are not shown. $\mathrm{AB}=$ Antisocial behavior. $\mathrm{EP}=$ Emotional problems

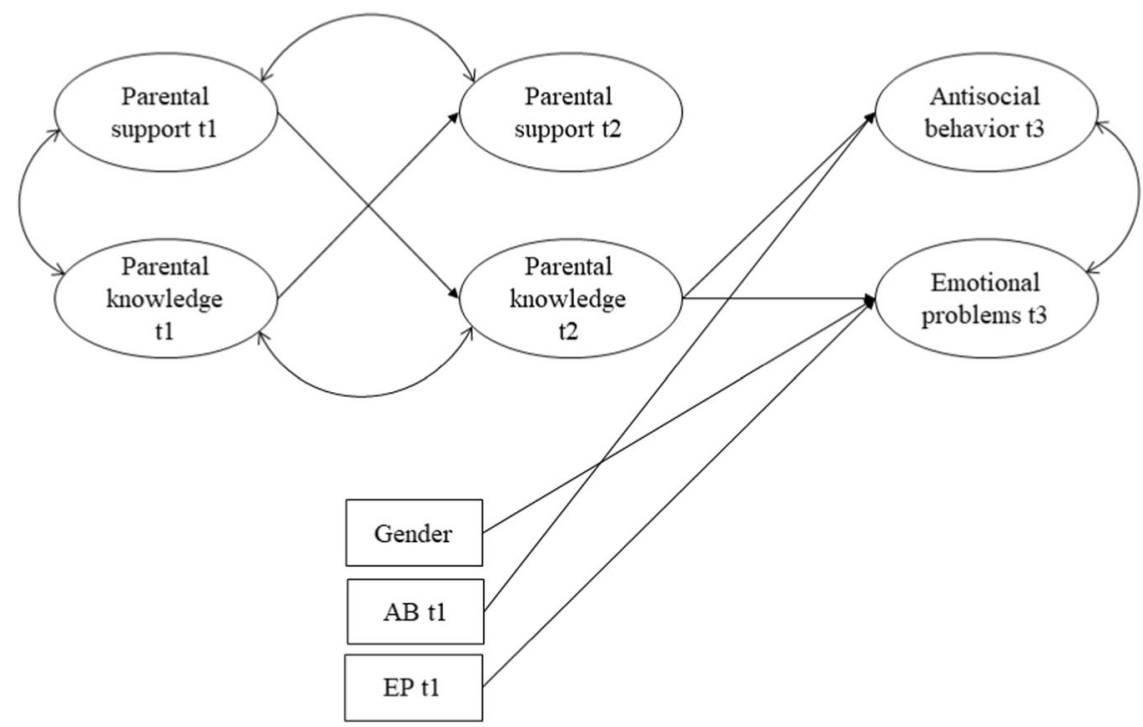

RMSEA $=0.04[0.03,0.04]$, SRMR $=0.06$. Significant positive correlations $(p<0.001)$ were found between the latent variables Support T1-Knowledge T1 $(r=0.68)$, Support T1-Support T2 $(r=0.33)$, Knowledge T1Knowledge T2 $(r=0.48)$, Antisocial behavior T3Emotional problems T3 $(r=0.39)$, as well as between the observed control variables Antisocial behavior T1Emotional problems T1 $(r=0.20)$. The correlation between the latent variables Support T2-Knowledge T2 $(r=0.05)$ was not significant $(p=0.227)$.

Table 2 displays standardized coefficients from the structural equation model and Fig. 2 shows the significant paths in the model. The results regarding the observed covariates indicated that gender significantly predicted emotional problems (females showed higher levels of emotional problems than males), $\mathrm{T} 1$ antisocial behavior significantly predicted antisocial behavior in T3 and T1 emotional problems significantly predicted emotional problems in T3, both in a positive direction. For the main variables of the model, results indicated that parental support and parental knowledge significantly predicted each other one year later, in a positive direction. Only parental knowledge in $\mathrm{T} 2$, not parental support, significantly and inversely predicted antisocial behavior and emotional problems in $\mathrm{T} 3$.

\section{Mediating Role of Parental Knowledge in the Association Between Parental Support and Antisocial Behavior and Emotional Problems}

To estimate the indirect effects, a combination of Maximum Likelihood (ML) and bootstrapping $(b=5000)$ were used in order to maximize accurate estimations. The results indicated significant indirect effects from parental support (T1) through parental knowledge (T2) on antisocial behavior $(\beta=-0.17, p<0.001 ; 95 \% \mathrm{CI}-0.25,-0.10)$ and emotional problems $(\beta=-0.08, p=0.018 ; 95 \%$ CI -0.14 , $-0.03)$. The indirect effects from parental knowledge through parental support on antisocial behavior $(\beta=0.05$, $p=0.181 ; 95 \%$ CI $-0.01,0.11)$ and emotional problems $(\beta=-0.04, p=0.263 ; 95 \%$ CI $-0.09,0.02)$ were not significant.

The sensitivity analysis testing the model with rulebreaking produced results that mirrored those reported above. The model showed very similar acceptable goodnessof-fit indexes, correlations and direct and indirect effects (both in direction and significance of coefficients). These results are available from the authors upon request.

\section{Discussion}

Developmental theory suggests that warm and supportive parent-child relationships are the basis for later child disclosure and parental knowledge and research has confirmed that parental knowledge is one of the most robust predictors of adolescent adjustment. The mediating role of parental knowledge between parental support and adolescent outcomes has been mostly studied regarding antisocial behavior and externalizing problems compared to emotional problems, and there is a gap in research about assessing those effects on both behavioral and emotional problems in adolescence from a longitudinal perspective. From a developmental and holistic-integrative approach, the study of the longitudinal interrelation of the main positive parenting practices influencing co-occurring behavioral and emotional problems is warranted to better understand adolescent development.

To address these gaps, the current study analyzed bidirectional relationships and longitudinal mediation effects 
of parental support and parental knowledge on both antisocial behavior (externalizing problems) and emotional problems (internalizing problems) in Spanish normative adolescents. In addition, cross-sectional and longitudinal relationships between externalizing and internalizing problems were analyzed in order to shed further light on patterns of adjustment problems displayed by youth at this developmental stage. Although antisocial behavior did not predict emotional problems and emotional problems did not predict antisocial behavior two years later, antisocial behavior and emotional problems were significantly and positively correlated in $\mathrm{T} 1$ as well as in $\mathrm{T} 3$. These results confirm the co-occurrence of both externalizing and internalizing problems in adolescence (Loeber \& Burke, 2011) and highlight the need to adapt prevention and intervention strategies accordingly (Ballester et al., 2020).

The findings indicated that parental support and parental knowledge were predictive of each other one year later, confirming the first hypothesis of the study. This finding is consistent with previous strong evidence indicating that parental support positively predicts parental knowledge (e.g., Liu et al., 2020; Yun et al., 2016). Evidence regarding the longitudinal effects of parental knowledge on parental support was not as consistent. Some studies have previously not found significant reciprocal, longitudinal relationships between parental acceptance and parental knowledge (Garthe et al., 2015), while others have found bi-directional connections between parental knowledge and positive parentchild relationships (Walters, 2019). The inconsistency regarding the effects of parental support might be due in part to the heterogeneity in the definition and, therefore, measure operationalization of the construct (e.g., support, warmth, acceptance, attachment) (Hoeve et al., 2009).

On the other hand, in the current study only parental knowledge at $\mathrm{T} 2$ was significantly related to antisocial behavior and emotional problems one year later. These findings confirm the role of parental knowledge in adolescence as a robust parenting-related predictor of both externalizing (Cutrín et al., 2019) and internalizing problems (Yap et al., 2014). Moreover, in line with other studies (Reitz et al., 2006), the effects of parental knowledge appeared to be stronger for externalizing than for internalizing problems in adolescence.

The results of this study did not show a direct influence of parental support on behavioral and emotional problems in mid-adolescence; hence, the second hypothesis was only partially supported. Previous research already identified the no significant direct effects of parental support on antisocial behavior (e.g., Cutrín et al., 2015) and emotional problems (e.g., Parra \& Oliva, 2006). Nevertheless, parental support indirectly predicted both antisocial behavior and emotional problems two years later, through the level of parental knowledge.
As proposed in the third hypothesis, the significance and confidence intervals of indirect effects showed a unidirectionality from parental support through parental knowledge on adolescent adjustment, and not the reverse pathway. As other studies have found, the establishment of a supportive and communicative family atmosphere in early adolescence seems to promote parental knowledge during mid-adolescence, which, in turn, is protective against both antisocial behavior (e.g., Yun et al., 2016) and emotional problems (e.g., Yan et al., 2017). These findings support developmental theory and reinforce the evidence about parental support as the basis of later parentaladolescent relationships (Collins \& Steinberg, 2008) and specifically of later parental knowledge, in line with previous research (e.g., Blodgett Salafia et al., 2009; Kerr et al., 2010; Tilton-Weaver, 2014).

These findings show that parental knowledge fully mediated the effects of parental support on externalizing and internalizing problems in Spanish adolescents. These findings confirm the results of previous cross-sectional research conducted in Spain regarding antisocial behavior (Cutrín et al., 2017) and provide novel evidence regarding the longitudinal effects of parental support through parental knowledge on emotional problems. Although parental support is not directly linked with externalizing and internalizing problems in adolescence, the results are indicative of the positive role of parental support in Spanish parenting styles (García \& Gracia, 2010), as it is the key variable for later adolescent disclosure and, subsequently, parental knowledge, which is, in turn, the key for preventing both behavioral and emotional problems in adolescence.

Due to the existing regional cultural diversity within Spain, future intraregional studies could be of interest. Future cross-national research should also examine whether the influence of parental support on later communication patterns, willingness to disclose information, and parental knowledge (as suggested by previous research; e.g., Liu et al., 2020; Tilton-Weaver, 2014) is stronger in Spanish families than in families in other cultural contexts (e.g., in North Europe).

\section{Practical Implications}

Prevention of adolescent behavioral and emotional problems should be approached as a public health issue and prioritized within communities and by social policy (Kim et al., 2015). Preventive strategies should be applied to avoid early engagement in antisocial behavior and manifestation of emotional problems, in order to promote a healthy, well-adjusted development throughout adolescence. Many preventive efforts so far have been aimed at the family as the main context for socialization and parenting practices have been a target of preventive 
interventions (e.g., Familias: Preparando la Nueva Generación, Marsiglia et al., 2014; Programa de Competencia Familiar, Orte et al., 2013; Constuir Lo Cotidiano, Torío et al., 2015).

The mediation effects found in the current study together with developmental theory (e.g., Granic et al., 2003) and previous research on parenting practices support the design and implementation of early prevention approaches. Interventions providing parental support can be protective for antisocial behavior and emotional problems in Spanish adolescents since it is a foundation of positive parent-child relationships later in life. Ultimately, the goal of preventive efforts to improve behavioral and emotional adjustment in adolescence should be to strengthen parental knowledge. In addition, positive parenting practices can promote the natural decline of antisocial behavior in the general population of adolescents (Buck \& Dix, 2014). As this study was conducted with adolescents from the general population, it is important to highlight that parenting behaviors that might successfully prevent the onset of antisocial behavior (such as parental support; Zheng \& Cleveland, 2013), might not reduce such behavior once it is established. Thus, the findings indicate the need to implement early and universal prevention interventions.

\section{Limitations}

The current study presents some limitations that must be considered for the appropriate interpretation of the findings and should be addressed in future research. The use of only student self-reports can lead to shared method variance, which may have partially influenced the results. Parents did not participate in the study and their responses to the same questions answered by the youth could have enriched the findings. Future sample designs of research studies on this topic could benefit from parent-child dyads. In addition, students at higher risk were more likely to drop out of the study, which may have affected the generalizability of findings. The study only included schoolenrolled students, having a sample that includes nonschool attending youth would have provided a more accurate assessment of their experiences with delinquency. Additionally, it should be taken into account that levels of posttest attrition were significantly higher among students reporting more antisocial behavior at the pretest. Antisocial behavior is associated with poor school performance and early school dropout, as well as a pattern of defiance towards authority, all of which may have been reasons for attrition in this study. Finally, personality traits and differences across genders were not considered in the current study. Future longitudinal studies that address these limitations and begin at earlier developmental stages will be beneficial developing knowledge on how parenting practices influence children's behavior from childhood to late adolescence.

\section{Conclusion}

Developmental theory and previous research have proposed that parental support leads to higher parental knowledge, which, in turn, influences adolescent adjustment. These mediation effects have been confirmed mostly regarding antisocial behavior and externalizing problems, but there is a lack of evidence on emotional and internalizing problems. The current study addressed the longitudinal interrelation of parental support and parental knowledge, as the main positive parenting practices, and their potential effects on both behavioral and emotional problems. Because this study was based on a developmental and holistic-integrative approach, the findings could contribute to a better understanding of adolescent development by disentangling how parental support and parental knowledge are longitudinally interrelated and how complex their influence is on adolescent adjustment. The current study confirmed the cooccurrence of behavioral and emotional problems in Spanish adolescents and the bi-directional relationships between positive parenting practices. One of the main findings confirmed that supportive parenting practices involving warmth, closeness, and open communication indirectly prevent adolescents' antisocial behaviors through increasing parental knowledge. The main novel finding was that the same longitudinal parenting relationships influenced adolescents' internalizing problems such as anxiety and depression. These findings have specific implications for practice, prevention interventions, research and policy, not only for adolescents but also for their parents. This study highlights the role of parental knowledge as the key variable influencing antisocial behavior and emotional problems. Therefore, these findings can contribute to the development of strategies, at both behavioral and emotional levels, for adolescents and their parents, by indicating that increasing parental knowledge should be the target of educationalprevention programs.

Authors' Contributions O.C. conceived of the study, participated in its design and coordination, performed the statistical analysis and interpretation of the data, and drafted the manuscript; L.M. performed the measurement, participated in the interpretation of the data, and helped to draft the manuscript; Y.C. contributed to draft the manuscript; S.K. participated in the interpretation of the data and helped to draft the manuscript; F.F.M. contributed to draft the manuscript; J.A.G.F. conceived of the study, participated in the design and coordination of the study. All authors read and approved the final manuscript.

Funding This study was supported by the Consellería de Cultura, Educación e Ordenación Universitaria (Xunta de Galicia) under the Programa de Axudas á etapa predoutoral da Xunta de Galicia and the 
Programa de Axudas á etapa posdoutoral da Xunta de Galicia. The study was also supported by the Axuda para a consolidación e estruturación de unidades de investigación competitivas e outras accións de fomento nas universidades do SUG (GRC, 2018; Consellería de Cultura, Educación e Ordenación Universitaria, Xunta de Galicia) and by FEDER/Ministerio de Ciencia, Innovación y Universidades Agencia Estatal de Investigación (Grant PSI2015-65766-R).

Data Sharing Declaration The datasets generated and/or analyzed during the current study are not publicly available but are available from the corresponding author on reasonable request.

Funding Open Access funding provided thanks to the CRUE-CSIC agreement with Springer Nature.

\section{Compliance with Ethical Standards}

Conflict of Interest The authors declare no competing interests.

Research Involving Human Participants and/or Animals All procedures performed in studies involving human participants were in accordance with the ethical standards of the institutional and/or national research committee and with the 1964 Helsinki declaration and its later amendments or comparable ethical standards. This article does not contain any studies with animals performed by any of the authors.

Informed Consent Informed consent was obtained from all individual participants included in the study.

Ethical Approval This study was approved by the Autonomous Community's Government and met ethical standards established by the host university's bioethics committee.

Publisher's note Springer Nature remains neutral with regard to jurisdictional claims in published maps and institutional affiliations.

Open Access This article is licensed under a Creative Commons Attribution 4.0 International License, which permits use, sharing, adaptation, distribution and reproduction in any medium or format, as long as you give appropriate credit to the original author(s) and the source, provide a link to the Creative Commons license, and indicate if changes were made. The images or other third party material in this article are included in the article's Creative Commons license, unless indicated otherwise in a credit line to the material. If material is not included in the article's Creative Commons license and your intended use is not permitted by statutory regulation or exceeds the permitted use, you will need to obtain permission directly from the copyright holder. To view a copy of this license, visit http://creativecommons. org/licenses/by/4.0/.

\section{References}

Álvarez-García, D., García, T., Barreiro-Collazo, A., Dobarro, A., \& Antúnez, Á. (2016). Parenting style dimensions as predictors of adolescent antisocial behavior. Frontiers in Psychology, 7, 1383 https://doi.org/10.3389/fpsyg.2016.01383.

Bacchini, D., Concetta, M. M., \& Affuso, G. (2011). Effects of parental monitoring and exposure to community violence on antisocial behavior and anxiety/depression among adolescents.
Journal of Interpersonal Violence, 26(2), 269-292. https://doi. org/10.1177/0886260510362879.

Ballester, L., Sánchez-Prieto, L., Orte, C., \& Vives, M. (2020). Preventing internalizing and externalizing symptoms in adolescents through a short prevention programme: An analysis of the effectiveness of the universal strengthening families program 1114. Child and Adolescent Social Work Journal. Advance online publication. https://doi.org/10.1007/s10560-020-00711-2.

Bentler, P. M., \& Chou, C. P. (1987). Practical issues in structural modeling. Sociological Methods \& Research, 16(1), 78-117. https://doi.org/10.1177/0049124187016001004.

Blodgett Salafia, E. H., Gondoli, D. M., \& Grundy, A. M. (2009). The longitudinal interplay of maternal warmth and adolescents' selfdisclosure in predicting maternal knowledge. Journal of Research on Adolescence, 19(4), 654-668. https://doi.org/10.1111/j.15327795.2009.00615.x.

Bronfenbrenner, U. (2005). The bioecological theory of human development. In U. Bronfenbrenner (Ed.), Making human beings human: Bioecological perspectives on human development ( $\mathrm{pp}$. 3-15). Thousand Oaks, CA: Sage Publications.

Buck, K. A., \& Dix, T. (2014). Parenting and naturally occurring declines in the antisocial behavior of children and adolescents: A process model. Journal of Family Theory \& Review, 6(3), 257-277. https://doi.org/10.1111/jftr.12042.

Burfeind, J., \& Bartusch, D. J. (2016). Juvenile delinquency: An integrated approach (3rd ed.). New York, NY: Routledge/Taylor \& Francis Group.

Calafat, A., García, F., Juan, M., Becoña, E., \& Fernández-Hermida, J. R. (2014). Which parenting style is more protective against adolescent substance use? Evidence within the European context. Drug and Alcohol Dependence, 138, 185-192. https://doi.org/10. 1016/j.drugalcdep.2014.02.705.

Collins, W. A., \& Steinberg, L. (2008). Adolescent development in interpersonal context. In W. Damon \& R. M. Lerner (Eds.), Child and adolescent development: An advanced course (pp. 551-590). Hoboken, NJ: John Wiley \& Sons Inc.

Compas, B. E. (2004). Processes of risk and resilience during adolescence: Linking contexts and individuals. In R. M. Lerner \& L. Steinberg (Eds.), Handbook of adolescent psychology (2nd ed., pp. 263-296). Hoboken, NJ: John Wiley \& Sons. https://doi.org/ 10.1002/9780471726746.ch9.

Cutrín, O., Gómez-Fraguela, J. A., \& Luengo, M. A. (2015). Peergroup mediation in the relationship between family and juvenile antisocial behavior. The European Journal of Psychology Applied to Legal Context, 7(2), 59-65. https://doi.org/10.1016/j.ejpal. 2014.11.005.

Cutrín, O., Gómez-Fraguela, J. A., \& Sobral, J. (2017). Two faces of parental support: risk and protection for antisocial youth depending on parental knowledge. Journal of Child and Family Studies, 26(1), 296-305. https://doi.org/10.1007/s10826-0160559-6.

Cutrín, O., Maneiro, L., Sobral, J., \& Gómez-Fraguela, J. A. (2019). Longitudinal validation of a new measure to assess parental knowledge and its sources in Spanish adolescents. Journal of Child and Family Studies, 28(5), 1220-1235. https://doi.org/10. 1007/s10826-019-01366-z.

Dane, A., Kennedy, R., Spring, M., Volk, A., \& Marini, Z. (2012). Adolescent beliefs about antisocial behavior: Mediators and moderators of links with parental monitoring and attachment. The International Journal of Emotional Education, 4, 4-26. https://www.um.edu.mt/ijee.

De Kemp, R. A. T., Overbeek, G., de Wied, M., Engels, R. C. M., \& Scholte, R. H. J. (2007). Early adolescent empathy, parental support, and antisocial behaviour. The Journal of Genetic Psychology, 168(1), 5-18. https://doi.org/10.3200/GNTP.168.1.5-18. 
DeLisi, M. (2016). Measuring the cost of crime. In B. M. Huebner \& T. S. Bynum (Eds.), The handbook of measurement issues in criminology and criminal justice (pp. 416-433). Chichester, UK: John Wiley \& Sons. https://doi.org/10.1002/9781118868799.ch18.

Eaton, N. R., Krueger, R. F., Johnson, W., McGue, M., \& Iacono, W. G. (2009). Parental monitoring, personality, and delinquency: Further support for a reconceptualization of monitoring. Journal of Research in Personality, 43(1), 49-59. https://doi.org/10.1016/ j.jrp.2008.10.006.

Fletcher, A. C., Steinberg, L., \& Williams-Wheeler, M. (2004). Parental influences on adolescent problem behavior: Revisiting Stattin and Kerr. Child Development, 75(3), 781-796. https://doi. org/10.1111/j.1467-8624.2004.00706.x.

García, F., \& Gracia, E. (2010). ¿Qué estilo de socialización parental es el idóneo en España? Un estudio con niños y adolescentes de 10 a 14 años [What is the optimum parental socialisation style in Spain? A study with children and adolescents aged 10-14 years]. Infancia y Aprendizaje, 33(3), 365-384. https://doi.org/10.1174/ 021037010792215118.

Garthe, R. C., Sullivan, T., \& Kliewer, W. (2015). Longitudinal relations between adolescent and parental behaviors, parental knowledge, and internalizing behaviors among urban adolescents. Journal of Youth and Adolescence, 44(4), 819-832. https://doi. org/10.1007/s10964-014-0112-0.

Granic, I., Dishion, T. J., \& Hollenstein, T. (2003). The family ecology of adolescence: A dynamic systems perspective on normative development. In G. R. Adams \& M. D. Berzonsky (Eds.), Blackwell handbook of adolescence (pp. 60-91). Malden, MA: Blackwell Publishing. https://doi.org/10.1002/ 9780470756607.ch4.

Hancock, G. R., \& Liu, M. (2012). Bootstrapping standard errors and data-model fit statistics in structural equation modeling. In R. H. Hoyle (Ed.), Handbook of structural equation modeling (pp. 296-306). New York, NY: The Guilford Press.

Hoeve, M., Dubas, J. S., Eichelsheim, V. I., van der Laan, P. H., Smeenk, W., \& Gerris, J. R. M. (2009). The relationship between parenting and delinquency: A meta-analysis. Journal of Abnormal Child Psychology, 37(6), 749-775. https://doi.org/10.1007/ s10802-009-9310-8.

Hu, L. T., \& Bentler, P. M. (1999). Cutoff criteria for fit indexes in covariance structure analysis: Conventional criteria versus new alternatives. Structural Equation Modeling, 6(1), 1-55. https:// doi.org/10.1080/10705519909540118.

Hughes, E. K., \& Gullone, E. (2008). Internalizing symptoms and disorders in families of adolescents: A review of family systems literature. Clinical Psychology Review, 28(1), 92-117. https://doi. org/10.1016/j.cpr.2007.04.002.

Kerr, M., \& Stattin, H. (2000). What parents know, how they know it, and several forms of adolescent adjustment: Further support for a reinterpretation of monitoring. Developmental Psychology, 36(3), 366-380. https://doi.org/10.1037/0012-1649.36.3.366.

Kerr, M., Stattin, H., \& Burk, W. J. (2010). A reinterpretation of parental monitoring in longitudinal perspective. Journal of Research on Adolescence, 20(1), 39-64. https://doi.org/10.1111/j. 1532-7795.2009.00623.x.

Kim, B. K. E., Gilman, A. B., \& Hawkins, J. D. (2015). School- and community-based preventive interventions during adolescence: Preventing delinquency through science-guided collective action. In J. Morizot \& L. Kazemian (Eds.), The development of criminal and antisocial behavior: Theory, research and practical applications (pp. 447-460). Cham, Switzerland: Springer International Publishing. https://doi.org/10.1007/978-3-31908720-7_28.

Laird, R. D., \& Zeringue, M. M. (2019). Parental knowledge and child disclosure as they relate to prosocial and antisocial behaviors. In D. J. Laible, G. Carlo, \& L. M. Padilla-Walker (Eds.), Oxford handbook of parenting and moral development (pp. 319-338). New York, NY: Oxford University Press.

Liu, D., Chen, D., \& Brown, B. B. (2020). Do parenting practices and child disclosure predict parental knowledge? A meta-analysis. Journal of Youth and Adolescence, 49(1), 1-16. https://doi.org/ 10.1007/s10964-019-01154-4.

Loeber, R., \& Burke, J. D. (2011). Developmental pathways in juvenile externalizing and internalizing problems. Journal of Research on Adolescence, 21(1), 34-46. https://doi.org/10.1111/j. 1532-7795.2010.00713.x.

Luengo, M. A., Otero-López, J. M., Romero, E., Gómez-Fraguela, J. A., \& Tavares-Filho, E. T. (1999). Análisis de ítems para la evaluación de la conducta antisocial: Un estudio transcultural [Item analysis in the assessment of antisocial behavior: a crooscultural study]. Revista Iberoamericana de Diagnóstico y Evaluación Psicológica, 1, 21-36. Retrieved from http://www.aidep. org/03_ridep/ridep.html.

Magnusson, D., \& Stattin, H. (2006). The person in context: A holistic-interactionistic approach. In R. M. Lerner \& W. Damon (Eds.), Handbook of child psychology: Vol. 1. Theoretical models of human development (6th ed., pp. 400-464). Hoboken, NJ: John Wiley \& Sons. https://doi.org/10.1002/9780470147658. chpsy0108.

Marsiglia, F. F., Williams, L. R., Ayers, S. L., \& Booth, J. M. (2014). Familias: Preparando la Nueva Generación: A randomized control trial testing the effects on positive parenting practices. Research on Social Work Practice, 24(3), 310-320. https://doi. org/10.1177/1049731513498828.

Ministerio de Sanidad, Consumo y Bienestar Social \& Instituto Nacional de Estadística (2017). Encuesta Nacional de Salud ENSE: 2017. Serie informes monográficos 1: Salud mental [ENSE National Health Survey: 2017. Monographic report series 1: Mental health]. Retrieved from https://www.mscbs.gob.es/esta dEstudios/estadisticas/encuestaNacional/encuestaNac2017/ SALUD_MENTAL.pdf.

Moreno, C., Ramos, P., Rivera, F., Sánchez-Queija, I., Jiménez-Iglesias, A., García- Moya, I., Moreno-Maldonado, C., Paniagua, C., Villafuerte-Díaz, A., Ciria-Barreiro, E., Morgan, A., \& Leal-López, E. (2019). La adolescencia en España: salud, bienestar, familia, vida académica y social. Resultados del Estudio HBSC 2018 [Adolescence in Spain: health, wellness, family, academic and social life. Results of the HBSC-2018 study]. Ministerio de Sanidad, Consumo y Bienestar Social. Retrieved from https://www.mscbs.gob. es/sanidad/portada/home.htm.

Oliva, A., Parra, Á., Sánchez-Queija, I. \& \& López, F. (2007). Estilos educativos materno y paterno: Evaluación y relación con el ajuste adolescente [Maternal and paternal parenting styles: assessment and relationship with adolescent adjustment]. Anales de Psicología, 23(1), 49-56. Retrieved from http://www.um.es/analesps.

Orte, C., Ballester, L., \& March, M. X. El enfoque de lacompetencia familiar, una experiencia de trabajo socioeducativo con familias [The family competence approach, an experience of socioeducational work withfamilies]. Pedagogía social. Revista Interuniversitaria, 21, 13-37. Retrieved from http://www.redalyc.org.

Ortuño-Sierra, J., Fonseca-Pedrero, E., Paíno, M., I Riba, S. S., \& Muñiz, J. (2015). Screening mental health problems during adolescence: Psychometric properties of the Spanish version of the Strengths and Difficulties Questionnaire. Journal of Adolescence, 38, 49-56. https://doi.org/10.1016/j.adolescence. 2014.11.001.

Parra, A., \& Oliva, A. (2006). Un análisis longitudinal sobre las dimensiones relevantes del estilo parental durante la adolescencia [Relevant dimensions of parenting style during adolescence: A longitudinal study]. Infancia y Aprendizaje / Journal for the Study of Education and Development, 29(4), 453-470. https://doi.org/ $10.1174 / 021037006778849594$. 
Pinquart, M. (2017). Associations of parenting dimensions and styles with internalizing symptoms in children and adolescents: A metaanalysis. Marriage \& Family Review, 53(7), 613-640. https://doi. org/10.1080/01494929.2016.1247761.

Reitz, E., Deković, M., \& Meijer, A. M. (2006). Relations between parenting and externalizing and internalizing problem behaviour in early adolescence: Child behaviour as moderator and predictor. Journal of Adolescence, 29(3), 419-436. https://doi.org/10.1016/ j.adolescence.2005.08.003.

Stattin, H., \& Kerr, M. (2000). Parental monitoring: A reinterpretation. Child Development, 71(4), 1072-1085. https://doi.org/10.1111/ 1467-8624.00210.

Tilton-Weaver, L. (2014). Adolescents' information management: Comparing ideas about why adolescents disclose to or keep secrets from their parents. Journal of Youth and Adolescence, 43(5), 803-813. https://doi.org/10.1007/s10964-013-0008-4.

Torío, S., Peña, J. V., Inda, M., Fernández, C. M., \& Rodríguez, C. (2015). Evaluation of the Building Everyday Life positive parenting programme. Journal of Children's Services, 10(2), 173-184. https://doi.org/10.1108/JCS-07-2014-0035.

Walters, G. D. (2019). Mothers and fathers, sons and daughters: Parental knowledge and quality of the parent-child relationship as predictors of delinquency in same- and cross-sex parent-child dyads. Journal of Child and Family Studies, 28(7), 1850-1861. https://doi.org/10.1007/s10826-019-01409-5.

Yan, J., Han, Z. R., Tang, Y., \& Zhang, X. (2017). Parental support for autonomy and child depressive symptoms in middle childhood: The mediating role of parent-child attachment. Journal of Child and Family Studies, 26(7), 1970-1978. https://doi.org/10.1007/ s10826-017-0712-x.

Yap, M. B. H., Pilkington, P. D., Ryan, S. M., \& Jorm, A. F. (2014). Parental factors associated with depression and anxiety in young people: A systematic review and meta-analysis. Journal of Affective Disorders, 156, 8-23. https://doi.org/10.1016/j.jad. 2013.11.007.

Yun, H., Cui, M., \& Blair, B. L. (2016). The mediating roles of adolescent disclosure and parental knowledge in the association between parental warmth and delinquency among Korean adolescents. Journal of Child and Family Studies, 25(8), 2395-2404. https://doi.org/10.1007/s10826-016-0425-6.

Zheng, Y., \& Cleveland, H. H. (2013). Identifying gender-specific developmental trajectories of nonviolent and violent delinquency from adolescence to young adulthood. Journal of Adolescence, 36(2), 371-381. https://doi.org/10.1016/j.adolescence. 2012.12.007.
Olalla Cutrín is an Assistant Professor at the Universidade de Santiago de Compostela (Spain). Her major research interests include negative parenting practices and antisocial peers as risk factors for antisocial behavior in adolescence.

Lorena Maneiro is a postdoctoral researcher of the Universidade de Santiago de Composela doing her research at the Leiden University (The Netherlands). Her major interests include development of antisocial behavior in foster care adolescents.

Yasmynn Chowdhury is a $\mathrm{PhD}$ student at the University of Oxford (United Kingdom). Her major research interests include cultural and anthropology determinants of behavior.

Stephen S. Kulis is Cowden Distinguished Professor of Sociology at Arizona State University (United States). His major research interests include cultural processes in health disparities and cultural adaptation of prevention programs for ethnic minority youth to prevent risk behaviors in adolescence.

Flavio F. Marsiglia is Regents' Professor at the Arizona State University (United States). His major research interests include translational intervention health research and program implementation to prevent substance use especially in Hispanic adolescents.

José Antonio Gómez Fraguela is a Professor at the Universidade de Santiago de Compostela (Spain). His major research interests include implementation of programs to prevent risk behaviors in childhood and adolescence and risk management in juvenile offenders. 